\title{
A Duopoly Model of Corporate Social Responsibility and Location Choice*
}

\author{
Alberto Balboni\# and Fabio Balboni§ \\ \#University of Paris Dauphine. E-mail contact: albertobalboni@yahoo.fr \\ §University of Bologna, LSE. E-mail contact: f.balboni@unibo.it \\ JEL codes: C72, D43, L13, L15, L22, M14 \\ Keywords: Corporate Social Responsibility, Duopoly, Minimum Standards, \\ Location, Vertical Product Differentiation
}

September 2008

\begin{abstract}
We adopt a framework of vertical differentiation to study the issue of Corporate Social Responsibility (CSR). We develop a model of duopoly in a two-country setting, in which firms choose the country of location, the level of CSR and finally compete in the market à la Bertrand. We show that: i) at equilibrium the two firms choose different levels of CSR, i.e. an "ethical" and a "neutral" firm coexist in the market; ii) regardless of its location choice, the "neutral" firm undertakes a level of CSR equal to the minimum international standard; iii) the location choice of both the "ethical" and the "neutral" firm depends on the relative costs of CSR in the two countries; in addition the choice of the "ethical" firm is influenced by the distribution of consumers' tastes for CSR, while the choice of the "neutral" firm is affected by the level of the minimum international standard for CSR.
\end{abstract}

\footnotetext{
${ }^{*}$ We thank Gianpaolo Rossini for helpful comments. Of course all remaining errors and omissions are entirely our own.
} 


\section{Introduction}

\subsection{A short review of the literature}

Corporate Social Responsibility (CSR) includes all the "situations where the firm goes beyond compliance and engages in actions that appear to further some social good, beyond the interests of the firm and that which is required by law" (McWilliams et al. [2006]). ${ }^{1}$ Hence, the fundamental idea behind CSR is that companies incur responsibilities to society beyond maximization of profit and should integrate social and environmental considerations in their decision making processes.

The issue of CSR has gained an increasing importance over the past thirty years and it is now widely discussed in newspapers and business school curricula. Furthermore, there is widespread evidence that consumers care about CSR when choosing where to shop (see, among others, Becchetti and Rosati [2005]). However, until recently only few theoretical works attempted to integrate the issue of CSR in the economic literature. The contrast between the increasing empirical relevance of CSR and the lack of economic analysis of this phenomenon led some authors to argue that the "challenge of the economic literature is to incorporate this new feature into its theoretical framework" (Becchetti, Giallonardo and Tessitore [2005]).

One of the first works which studied CSR from an economic perspective is the paper by McWilliams and Siegel (2002), which focused on the relationship between market structure and CSR and on the implications of CSR as regards the strategic behavior of firms. In that paper CSR is seen as a differentiation strategy for the firms in response to the sophistication of consumers' demand towards more ethical products. The first conclusion of the paper is that CSR should be "neutral" on profits, i.e. at equilibrium socially responsible (SR) firms and non-SR firms make identical profits. ${ }^{2}$ The second is that certain firm/industry-specific patterns in the provision of CSR should emerge, depending mainly on the characteristics of the products, on the market structure, on the level and the type of competition. For example, a high level of CSR is likely to be associated with the following elements: a high level of product differentiation in the industry (which normally comes from a more sophisticated consumers' demand), a high level of advertising (since CSR activities need to be advertised in order to be promoted), experience-goods (i.e. products that must be consumed before their value is known, for which advertising is crucial), high

\footnotetext{
${ }^{1}$ There is not one single definition of CSR on which there is consensus in the literature. Another possible definition is the following: CSR is a "concept whereby companies integrate social and environmental concerns in their business operations and in their interaction with their stakeholders on a voluntary basis" (European Commission, Green Paper on CSR [2001]). Differently, the working group of the ISO 26000 on Social Responsibility defines CSR as "the responsibility of an organization for the impacts of its decisions and activities on society and the environment through transparent and ethical behavior that is consistent with sustainable development and the welfare of society; takes into account the expectations of stakeholders; is in compliance with applicable law and consistent with international norms of behavior; and is integrated throughout the organization".

${ }^{2}$ When CSR is based only on profit motivations and not on ethical considerations, this result has to be verified. In fact, if SR firms make higher profits, more firms will start providing CSR, and this process will go on until both types of firms have to attain identical profits (the same reasoning works if non-SR firms make higher profits at the beginning).
} 
consumers' incomes (because the sophistication of costumers' demand is likely to be positively related to income), high prices of substitutes goods (in fact, if these are sold at a much lower price, the CSR features embedded in the product would not help gain significant market shares), large size of firms (because of possible scale economies in the provision of CSR) and finally multi-product firms (because of possible scope economies).

Following this early contribution, there has been a surge of studies which concentrated on the role of CSR as a differentiation strategy. These papers developed the idea that there is a demand for a more ethical behavior by firms, in some of the markets where they compete (e.g. goods, capital, labor), and thus CSR can be used as a strategy to attain higher profits. ${ }^{3}$ In particular, some authors (Bagnoli and Watts [2003], Besley and Gathak [2007]) viewed CSR as the private provision by firms of a local public good (e.g. social networks, community development)/reduction of a public bad (e.g. pollution); others (Becchetti, Giallonardo and Tessitore [2005], Becchetti, Federico and Solferino [2005], Manasakis, Mitrokostas and Petrakis [2007], Mitrokostas and Petrakis [2007]) as a differentiation strategy in the market of products, in response to consumers' demand for goods that embed certain "ethical" characteristics; some again (Brekke and Nyborg [2004]) viewed CSR as a labor market screening strategy to attract the most motivated and productive employees; others (Baron [2007]) as a strategy to attract "ethical" investors and, finally, some (Maxwell, Lyon and Hackett [2000], Baron [2001]) as a strategy used by firms to preempt government regulatory intervention in response to the requests of lobby groups and the civil society.

All these contributions try in different ways to provide answers to a few key questions on CSR. The first one is whether the firms competing on the same market at equilibrium provide different levels of CSR (i.e. there is differentiation at equilibrium) or they provide the same level of CSR (i.e. there is no differentiation at equilibrium). The second one regards the effects of increased competition in the market on the level of CSR undertaken by firms. In fact Baumol (1991) argued that, the more competitive is the market, the less room there is for firms to undertake CSR because of the lack of extra-profits to spend on these activities. Finally, there is the question of whether CSR is welfare-enhancing or not, and what should governments do in order to maximize the increase in social welfare via CSR.

\subsection{This paper's approach to CSR modelling}

In the present paper we develop the idea of CSR as a differentiation strategy for the firms introducing a two-country setting, which to our knowledge is a novelty in the CSR literature. Our main reference is the model of duopoly differentiated by quality developed by Motta (1993), which we adapt to the issue of CSR. This framework has already been

\footnotetext{
${ }^{3}$ These works provide an indirect answer to the famous claim by Milton Friedman (1972). Friedman affirmed that firms should not undertake CSR because it shifts resources from the firms' most important objective, which is the maximization of shareholders' value (i.e. profit-maximization). However these theories have been able to show that in fact CSR, under certain circumstances (e.g. it is aligned with the firms' business operations or it caters certain consumers' demands), can help the firms increase their profits. For this reason, the theories in which CSR is seen as a profit-enhancing strategy are often referred to as the "neo-classical" theories of CSR.
} 
applied by Amacher, Koskela and Ollikainen (2004) to a similar problem (i.e. environmental quality competition and eco-labeling).

Before presenting our model, it is useful to quickly recall the main features and conclusions of the model developed by Motta (1993). There, the consumers present different tastes for quality and are uniformly distributed with unit density. There is no a priori upper bound to the level of quality, but there is lower bound to it, which could be interpreted as a minimum legal requirement. A further assumption is that the market is not covered, i.e. some consumers do not buy the differentiated good at all. ${ }^{4}$ The model comprises a two-stage game in which the firms first decide the level of quality of the differentiated good, and then compete on the market, either in prices (i.e. Bertand-Nash equilibrium) or in quantities (i.e. Cournot-Nash equilibrium). Four different cases are studied, assuming either fixed or variable costs of quality improvement.

The case which is more interesting for the purposes of our paper is the BertrandNash equilibrium (i.e. firms choose prices at the last stage of the game) with fixed costs of quality improvement (and no variable costs). In this case, Motta (1993) shows that, at equilibrium, the two firms choose different quality locations (i.e. there is differentiation at equilibrium). This confirms the results of a previous paper by Shaked and Sutton (1982), in which firms choose to differentiate their products even when costs of quality are zero, in order to relax price competition on the market. However, while in Shaked and Sutton (1982), with neither variable nor fixed costs of quality, one firm chooses the maximum quality possible and the other a level strictly higher than the minimum (i.e. the maximum differentiation equilibrium emerges), in Motta (1993), with fixed costs of quality, both firms choose a level of quality internal to the interval of possible qualities. Motta (1993) also shows that, should one remove the assumption of uncovered market, it would become optimal, for the firm which offers the lower quality, to set its quality to a level equal to the minimum requirement. This result corresponds to the one of Tirole (1988).

The Cournot-Nash equilibrium (i.e. firms choose quantities at the second stage of the game) yields less quality differentiation than the Bertrand-Nash one, since in the latter firms have a higher incentive to choose more distant quality specifications, due to the fiercer competition at the marketing stage of the game. Differently from Bonanno (1986) where firms choose not to differentiate when fixed costs of quality improvement do not exist, in Motta (1993) there is always quality differentiation at equilibrium, even if not maximum. However, Motta (1993) shows that an equilibrium with no differentiation would occur if one introduced an upper bound to quality choice and assumed that, when computed at this highest level, marginal costs of quality are not as high as the marginal revenues.

A framework of vertical differentiation has already been adopted in the economic literature of CSR, assuming that CSR is a feature embedded in the goods which induces the consumers to pay a higher price for it. From this perspective, CSR can be assimilated to quality. However it is worth noting that there is still some debate in the literature on which framework of differentiation (i.e. horizontal vs. vertical) is more appropriate to analyze the issue of CSR. Some authors (Becchetti, Giallonardo and Tessitore [2005]) propend for the

\footnotetext{
${ }^{4}$ This assumption has been made because, with full market coverage, the demand function cannot be inverted and the Cournot-Nash equilibrium cannot be analyzed.
} 
framework of horizontal differentiation, since empirical studies showed that consumers have their own preferred locus on the ethical segment, and do not necessarily prefer to have more CSR than less. Others (Mitrokostas and Petrakis [2007] among others) are favorable to a framework of vertical differentiation (i.e. more CSR is better for everyone). ${ }^{5}$ Our opinion is that, even if it is true that consumers might have different preferred locations on the ethical segment with respect to the different aspects of CSR considered separately (e.g. environmental protection, labor standards, gender issues, etc.), when CSR is considered in an holistic way it seems quite unrealistic to assume that there are consumers which, at a given price, prefer to buy the variety of the good with lower CSR content. For this reason, in this paper we adopt a framework of vertical differentiation. ${ }^{6}$

The remainder of the paper is organized as follows. Section 2 presents the basic model, analyses the market equilibrium in terms of the provision of CSR and introduces the problem of the location choice. Section 3 presents some exercises of comparative statics. Finally, section 4 concludes.

\section{The Model}

We consider a duopolistic market with two firms (1 and 2) producing a differentiated good. The goods produced by the two firms can differ in their CSR content i.e. the CSR activities undertaken by the firms and perceived by its customers. The CSR content of the good produced by firm $i$, with $i=1,2$, is denoted by $s_{i}$, and we assume, without loss of generality, that $s_{1} \geq s_{2}$ (cf. Tirole [1988] and Motta [1993]).

Following Tirole (1988) and Motta (1993), we suppose that consumers have the same (indirect) utility function, $U=v s-p$, if they buy one unit of the differentiated good and zero utility if they do not buy it. In this expression, $s$ and $p$ are respectively the CSR content and the price of the differentiated good. We suppose that consumers differ in their tastes with respect to the CSR content of the differentiated good. The term $v$ is the consumer's taste parameter, which can be interpreted as each consumer's marginal willingness to pay for CSR. Parameters $v$ are distributed with unit density over the interval

\footnotetext{
${ }^{5}$ It should be noted that Becchetti, in another paper (Becchetti, Federico and Solferino [2005]), implicitly accepts that there is at least one element of vertical differentiation in CSR, since in their paper consumers bear a cost only in case of a downward deviation from their preferred location in term of "ethical" content of the product, and not otherwise.

${ }^{6}$ One possible drawback in applying Motta (1993)'s model to the issue of CSR regards the result of differentiation at equilibrium. In fact, while in Motta (1993) at equilibrium the two firms choose different levels of quality, the empirical evidence of CSR shows a convergence of firms towards an "ethical" behavior, at least in the developed world (cf. the concept of "ethical imitation" in Becchetti, Giallonardo and Tessitore [2005]). However it can be shown (cf. Motta [1993]) that, if one introduces an upper bound to quality improvement and assumes that, when computed at this level, marginal costs of quality are not as high as marginal revenues, there will be no differentiation at equilibrium, with both firms choosing a level of quality equal to the highest possible level. The assumption of marginal costs lower than marginal revenues seems quite realistic in the study of CSR. In fact, since CSR has been exploited only recently as a differentiation strategy, it is plausible that each marginal innovation yields very high returns, much higher than the costs. This leads the majority of firms to undertake a similar level of CSR at equilibrium, corresponding to the current "frontier" of CSR.
} 
$\left[v_{B}, v_{H}\right]$, such that $v_{B}=v_{H}-1$. Similarly to Motta (1993), we assume that there is no upper bound to the possible level of CSR undertaken by firms, but there is a lower bound to it. ${ }^{7}$ This can be interpreted as a minimum legal requirement for CSR (e.g. a CSR standard) valid all over the world, which we denote as $s_{0} .{ }^{8}$ Differently from Motta (1993), we assume that the market is covered at equilibrium, which means that all consumers buy one unit of the differentiated good. This assumption has been made for simplicity of the calculus, and could be removed in a follow-up paper.

We can define $v_{12}$ as the taste parameter of the individual which is indifferent between buying the good with higher CSR content and buying the other one. For this individual we have $v_{12} s_{1}-p_{1}=v_{12} s_{2}-p_{2}$, from which we determine: $v_{12}=\frac{p_{1}-p_{2}}{s_{1}-s_{2}}$.

Then, we define as $v_{02}$ the taste parameter of the individual which is indifferent between buying the good with lower CSR content and not buying at all. Hence $v_{02} s_{2}-p_{2}=0$. From this we can find $v_{02}=p_{2} / s_{2}$ and derive the aggregate demand functions for goods 1 and 2:

$$
\begin{aligned}
& q_{1}=v_{H}-\frac{p_{1}-p_{2}}{s_{1}-s_{2}} \\
& q_{2}=\frac{p_{1}-p_{2}}{s_{1}-s_{2}}-\frac{p_{2}}{s_{2}}
\end{aligned}
$$

If at equilibrium $v_{B}>p_{2} / s_{2}$, then we can affirm that the market is covered because all the consumers with $v \in\left[v_{B}, v_{12}\right]$ buy good 2. In order to ensure that positive demands for the two goods exist, we must assume that the condition $p_{2} / s_{2}<v_{B}<\left(p_{1}-p_{2}\right) /\left(s_{1}-s_{2}\right)<v_{H}$ holds at equilibrium. With covered market, the demand functions for goods 1 and 2 are:

$$
\begin{aligned}
& q_{1}=v_{H}-\frac{p_{1}-p_{2}}{s_{1}-s_{2}} \\
& q_{2}=\frac{p_{1}-p_{2}}{s_{1}-s_{2}}-v_{B}
\end{aligned}
$$

These functions are easier to use than those with uncovered marked [1] but, as previously said, they have the drawback that they can't be inverted in order to study the Cournot-Nash equilibrium. Therefore, only the Bertrand-Nash equilibrium will be studied in this paper.

\footnotetext{
${ }^{7}$ Several authors, following McWilliams and Siegel (2002) argue that there is an upper bound to the level of CSR which can be undertaken by a firm. This level corresponds to the point when one additional "unit" of CSR does not bring any additional benefit to the society because of saturation. However for simplicity we prefer to follow the original framework used by Motta (1993).

${ }^{8}$ An example of this minimum global standard for CSR could be UN Global Compact, the world's largest CSR framework. The UN Global Compact comprises ten principles drawn from declarations which have been adopted by the majority of countries in the world (the 1948 Universal Declaration of Human Rights, the 1998 ILO Declaration on Fundamental Principles and Rights at Work, or the 1992 Rio Declaration on The Environment and Sustainability).
} 
The decision process of the two firms can be represented as a three-stage game. At the first stage, firms choose their location, in country A ("North") or in country B ("South"). At the second stage, firms choose the level of CSR $\left(s_{i}\right)$ simultaneously. Finally, at the third stage, a competitive process occurs and firms choose prices simultaneously, determining indirectly the equilibrium quantities of the two goods. The game is solved by backward induction.

The following assumptions have been made: 9

Assumption 1: $v_{H} \geq 2 v_{B}$. This ensures that there is a sufficient degree of heterogeneity among consumers (cf. Tirole [1988]). Note that, since $v_{B}=v_{H}-1$ (cf. page 5), we must have $0<v_{B}<1$ and $1<v_{H}<2$.

Assumption 2: $\left(v_{H}-2 v_{B}\right)\left(s_{1}^{*}-s_{2}^{*}\right) / 3<v_{B} s_{2}^{*}$. This ensures that the market is covered at equilibrium.

Assumption 3: $s_{1}^{*} \geq s_{2}^{*}$. Since we have assumed that $s_{1} \geq s_{2}$ (cf. page 5), this condition must also be verified at equilibrium.

\subsection{Marketing stage}

Using backward induction, we first study the last stage of the game, in which firms choose prices subject to their previous choices of CSR and location. We assume that there are only fixed costs of CSR and no variable costs. In other words, variable costs of production do not depend on the level of $\operatorname{CSR}\left(s_{i}\right)$, whereas fixed costs depend on it.

The assumption that the costs of CSR are fixed and do not depend on the level of production can be justified by the fact that in most cases these are up-front costs for a firm and only a smaller amount of them depends on the level of production. Hence, at the last stage of the game, the costs of CSR have already been sunk and there are only constant marginal costs of production. Without loss of generality, we assume that these costs are equal to zero. The study of the sub-game perfect Nash equilibrium at this stage gives the following results.

Proposition 1. At the third stage of the game, firm 1 sets a higher price and produces a larger output than firm 2. Hence, at equilibrium there is one firm (i.e. the "ethical" firm) that sells to the most ethical consumers, charging a higher price than the other one (i.e. the "neutral" firm), which sells to the rest of consumers.

\footnotetext{
${ }^{9}$ These assumptions regard the possible values of the exogenous parameters in the model. However Assumption 2 and Assumption 3 have been expressed using the terms $s_{1}^{*}$ and $s_{2}^{*}$, which are the levels of CSR chosen by, respectively, firm 1 and firm 2 at equilibrium (cf. sub-section 2.2). These are not exogenous variables per se, but are functions of the exogenous variables in the model (see Appendix). However we preferred to express Assumption 2 and Assumption 3 in this way for simplicity of notation.
} 
Proof. The expressions for the two firms' profits, with marginal costs of production equal to zero, are:

$$
\begin{aligned}
& \pi_{1}=p_{1}\left(v_{H}-\frac{p_{1}-p_{2}}{s_{1}-s_{2}}\right) \\
& \pi_{2}=p_{2}\left(\frac{p_{1}-p_{2}}{s_{1}-s_{2}}-v_{B}\right)
\end{aligned}
$$

Each firms maximize its profit in the price level. In order to determine the First Order Conditions (FOCs) for maximization, we compute the derivatives of profits with respect to prices and set them equal to zero:

$$
\begin{aligned}
& v_{H}+\frac{2 p_{1}-p_{2}}{s_{2}-s_{1}}=0 \\
& \frac{2 p_{1}-p_{2}}{s_{2}-s_{1}}-v_{B}=0
\end{aligned}
$$

Solving these expression for the prices, we obtain the reaction functions of the two firms:

$$
\begin{aligned}
& p_{1}=\frac{p_{2}-v_{H}\left(s_{1}-s_{2}\right)}{2} \\
& p_{2}=\frac{p_{1}+v_{B}\left(s_{1}-s_{2}\right)}{2}
\end{aligned}
$$

As expected, these reaction functions show that the prices of the two goods are strategic complements, since each price is an increasing function of the other, i.e. an increase of $p_{2}$ makes it more profitable for firm 1 to increase its price (cf. Varian [1992]).

After verifying that also the Second Order Conditions are respected, we solve the system of the reaction functions of the two firms and we find the level of the two prices at the BertrandNash equilibrium:

$$
\begin{aligned}
& p_{1}^{*}=\frac{\left(s_{1}-s_{2}\right)\left(2 v_{H}-v_{B}\right)}{3} \\
& p_{2}^{*}=\frac{\left(s_{1}-s_{2}\right)\left(v_{H}-2 v_{B}\right)}{3}
\end{aligned}
$$

Hence, at the last stage of the game, firms set prices at values given above. Since $v_{B}=v_{H}-1$ and $1<v_{H}<2$ (cf. Assumption 1), it follows that $2 v_{H}-v_{B}>v_{H}-2 v_{B}$. Hence, $p_{1}^{*}>p_{2}^{*}$ and both prices are positive at equilibrium.

Since quantities are given by the demand functions [2] it is useful to calculate $p_{1}^{*}-p_{2}^{*}$ at the equilibrium:

$$
p_{1}^{*}-p_{2}^{*}=\frac{\left(s_{1}-s_{2}\right)\left(v_{H}+v_{B}\right)}{3}
$$

Hence, at equilibrium prices, the outputs of goods 1 and 2 are, respectively:

$$
q_{1}^{*}=\frac{2 v_{H}-v_{B}}{3} ; q_{2}^{*}=\frac{v_{H}-2 v_{B}}{3}
$$


Once again, since $v_{B}=v_{H}-1$ and $1<v_{H}<2$, we have $2 v_{H}-v_{B}>v_{H}-2 v_{B}$, and thus $q_{1}^{*}>q_{2}^{*}$. Assumption $1\left(v_{H} \geq 2 v_{B}\right)$ ensures that the output of firm 2 is positive.

Finally, it is interesting to note that the outputs of the two firms at the Bertrand-Nash equilibrium depend only on the distribution of consumers and not on the levels of CSR decided at the second stage of the game (see expressions [8]).

\subsection{The choice of CSR levels}

Now we can study the second stage of the game, i.e. the choice of the level of CSR embedded in the good sold. Firms maximize their profits subject to their previous choice of location. Profits are given by revenues, computed at the Bertrand-Nash equilibrium, less costs and can be written as follows:

$$
\pi_{i}=p_{i}^{*} q_{i}^{*}-S_{i}-\frac{F_{i}}{2} s_{i}^{2} \text { with } i=1,2
$$

We have previously assumed that variable costs of production are null. All costs are fixed, and come from two different sources.

The first component is given by $S_{i}$, which corresponds to the costs of compliance with the labor standards and the environmental regulations, existing in the country where the firm is located. Hence, $S_{i}$ depends only on the choice of the country of location by the firm and at this stage of the game $S_{i}$ is taken as given since the location is chosen in the first stage of the game.

The second component is given by $\left(F_{i} / 2\right) s_{i}^{2}$. These costs depend on the level of CSR undertaken by the firm and can be considered as fixed costs with respect to the quantity of the good sold by the firm. For these costs we assume a quadratic form, as often made in the literature on vertical differentiation (D'Aspremont et al. [1979]). This seems a realistic assumption in the context of CSR. In fact, the first "units" of CSR are the least costly because a firm can direct its efforts to the easily-achievable targets (the "low-hanging fruits"). Afterwards, the costs of additional interventions increase, until the firm comes to a point when additional "units" of CSR becomes extremely expensive. ${ }^{10}$ These costs should be interpreted as the costs of making CSR "visible" to the consumers and not only as the costs of "doing" CSR. In fact, CSR has to be somehow visible in order for the parameter $s_{i}$ to enter the consumers' utility function and induce the consumers to pay a higher price for the good. ${ }^{11}$ Hence, we can refer to $s_{i}$ as the "evident" CSR, and by reflection $\left(F_{i} / 2\right) s_{i}^{2}$ will be the costs of making it "visible" to consumers. ${ }^{12}$

\footnotetext{
${ }^{10}$ For more details see McWilliams and Siegel (2002), Husted and Salazar (2006).

${ }^{11}$ It should be noted that $s_{i}$ are "units" of CSR, and not monetary costs for the firm, as it is for $S_{i}$.

${ }^{12}$ In practical terms, we can identify these cost as the costs of implementation plus the costs of advertising and promoting CSR towards the external environment. In the existing literature on CSR this second component of the costs (i.e. advertising and promoting CSR) has been set equal to zero since, for large firms in particular, they are not very significant (cf. Manasakis, Mitrokostas and Petrakis [2007]). However in our paper we do not set them
} 
From the study of the second stage of the game we can conclude the following.

Proposition 2. At the second stage the game, firm 1 undertakes a level of CSR equal to $s_{1}^{*}=\frac{\left(2 v_{H}-v_{B}\right)^{2}}{9 F_{1}}$, while the other firm sets its level of CSR to the minimum required by international standards (i.e. $s_{2}^{*}=s_{0}$ ). Hence, at equilibrium there is differentiation in the levels of CSR, with firm 1 (i.e. the "ethical" firm) which sets a level of CSR higher than firm 2 (i.e. the "neutral" firm). ${ }^{13}$

Proof. Using the expressions of the prices and quantities at the Bertrand-Nash equilibrium, we can write the profits of the two firms:

$$
\begin{aligned}
& \pi_{1}=\frac{\left(s_{1}-s_{2}\right)\left(2 v_{H}-v_{B}\right)^{2}}{9}-\frac{F_{1}}{2} s_{1}^{2}-S_{1} \\
& \pi_{2}=\frac{\left(s_{1}-s_{2}\right)\left(v_{H}-2 v_{B}\right)^{2}}{9}-\frac{F_{2}}{2} s_{2}^{2}-S_{2}
\end{aligned}
$$

These need to be maximized with respect to the level of CSR.

As regards firm 2, we can easily see that $\pi_{2}$ decreases monotonically in $s_{2}$. Hence, firm 2 will always set CSR at the minimum level allowed, $s_{2}^{*}=s_{0} \cdot{ }^{14}$

As regards firm 1, the FOC to maximize $\pi_{1}$ is $\left(\frac{2 v_{H}-v_{B}}{3}\right)^{2}-F_{1} s_{1}=0$, from which we can derive the optimal level of CSR: $s_{1}^{*}=\frac{\left(2 v_{H}-v_{B}\right)^{2}}{9 F_{1}}$.

Assumption $3\left(s_{1}^{*} \geq s_{2}^{*}\right)$ ensures that at equilibrium firm 1 sets a higher level of CRS than firm 2, (i.e. the equilibrium with differentiation emerges). ${ }^{15}$ There is only one case in which the two firms at equilibrium set the same level of CSR, equal to the minimum international standard (i.e. the equilibrium with no differentiation emerges). ${ }^{16}$

equal to zero, because one of our objectives is precisely to see what happens when these costs differ from one country to another.

${ }^{13}$ Among the values authorized by Assumption 3, there is only one case in which the equilibrium with differentiation does not occur, which is when the minimum international standard $s_{0}$ (which is fixed exogenously in our model) is equal to $\left(2 v_{H}-v_{B}\right)^{2} / 9 F_{1}$. In this case, since the international standard is set at exactly the same level as the level chosen by firm 1, the two firms undertake the same level of CSR. Hence, the equilibrium with no differentiation emerges, i.e. both firms set the level of CSR equal to the minimum international standard $s_{0}$. However, we do not take into consideration this case in the remainder of the paper, since it occurs for one and only one particular combination of the exogenous variables.

${ }^{14}$ Of course this result would be different if we did not make the assumption that the market is covered. In fact when the market is covered consumers always buy the good and, since there are costs attached to CSR, the optimal strategy for the second firm is always to set CSR equal to the minimum level required by law.

${ }^{15}$ It's worth noting that the degree of differentiation emerging at equilibrium is not the maximum possible, since we have assumed quadratic fixed costs of CSR and no upper boundary for CSR.

${ }^{16}$ See Appendix and note 13 (above) for more details. 
It is interesting to note that the optimal level of CSR for the "ethical" firm decreases in the costs of making CSR "visible" to the consumers $\left(F_{1}\right)$. We will see in the following subsection that these costs depend on the firm's location choice, which is made in the first stage of the game. On the other hand, the optimal level of CSR for the "neutral" firm does not depend on its location choice, since it is always set at the minimum level allowed. Hence, the lower the costs for the "ethical" firm of making CSR "visible" to the consumers, and the lower the minimum international standard, the higher will be, at equilibrium, the degree of differentiation between the two firms in the provision of CSR.

\subsection{The Choice of Location}

Let's now turn to the first stage of the game, i.e. the choice of location of the two firms. There are two countries in which firms can locate, denoted as A and B. We assume that the costs of compliance with local norms and regulations and the costs of making CSR "visible" to the consumers depend on the choice of location in one country or the other, such that:

$$
\begin{aligned}
& S_{i}=S_{A} \text { and } F_{i}=F_{A} \text { if the firm } i \text { is located in country A; } \\
& S_{i}=S_{B} \text { and } F_{i}=F_{B} \text { if the firm } i \text { is located in country B. }
\end{aligned}
$$

By definition, $S_{i}$ depends on the country of location, because it represents the costs of compliance with country-specific norms and regulations. In addition, we assume that also $F_{i}$ depends on the country of location, and in particular that $S_{i}$ and $F_{i}$ are mutually dependent across countries. In fact, a firm that produces in a country with very low labor and environmental standards (low $S_{i}$ ) will probably incur in high costs of making a given level of CSR "visible" to its customers (high $F_{i}$ ), as a result of the lack of transparency, reliable indicators, infrastructure, accountable Civil Society Organizations (CSOs) to partner with, etc. In particular, these costs should be higher than those that the same firm would face in a country characterized by high labor and environmental standards, where it would be relatively easy for a firm to credibly commit on certain CSR activities and also relatively cheap to partner with other entities on CSR projects, exploiting the existing social network.

In concordance with this assumption on the relationship between $S_{i}$ and $F_{i}$ across countries, in our model we assume that the costs of compliance with local norms and regulations are higher in country A than in B $\left(S_{A}>S_{B}\right)$, while the costs of making CSR "visible" to the consumers are lower in A than in $\mathrm{B}\left(F_{A}<F_{B}\right)$. Thus, we can refer to country A as "North" and to country B as "South".

One important remark is that in our model we assume that there is no cross-country heterogeneity in the distribution of consumers' tastes for CSR, and no transport costs. This could represent a situation in which firms 1 and 2 are constrained to produce in country A or B, but sell their products all over the world, and the demand for their products coming from the rest of the world is overwhelming with respect to the demand coming from countries A and B. ${ }^{17}$ We made this assumption because the main objective of our paper is to

\footnotetext{
${ }^{17}$ An example of this could be the oil market, in which firms are constrained to produce in certain countries where the oil is present, but often sell only a small part of their products in this countries.
} 
study how the "costs" of CSR in different countries influence the choice of location of firms, in the simplest framework as possible. A further paper could investigate these issues in a more sophisticated context, introducing transport costs and heterogeneity in the distribution of consumers' tastes across countries.

From the study of the third stage of the game we can conclude the following.

Proposition 3. The profits of firm 2 (i.e. the "neutral" firm) are always higher when firm 1 (i.e. the "ethical" firm) settles in the country where the costs of making CSR "visible" (F) are lower (i.e. country "North"). The profits of the "ethical" firm are unaffected from the choice of location of the "neutral" firm, since it anticipates that the latter will always undertake a level of CSR equal to the minimum international requirement $s_{0}$.

Proof. If we substitute the optimal levels of CSR (see Proposition 2) in the expressions [10], we obtain the expressions of the profits at the second stage equilibrium:

$$
\begin{gathered}
\pi_{1}=\frac{\left(2 v_{H}-v_{B}\right)^{2}}{9}\left[\frac{\left(2 v_{H}-v_{B}\right)^{2}}{9 F_{1}}-s_{0}\right]-\frac{\left(2 v_{H}-v_{B}\right)^{4}}{162 F_{1}}-S_{1} \\
\pi_{2}=\frac{\left(v_{H}-2 v_{B}\right)^{2}}{9}\left[\frac{\left(2 v_{H}-v_{B}\right)^{2}}{9 F_{1}}-s_{0}\right]-\frac{F_{2}}{2} s_{0}^{2}-S_{2}
\end{gathered}
$$

The expressions above prove that the profits of firm 1 (the "ethical" firm) are not affected by the choice of location of firm 2 (since they do not depend neither on $F_{2}$ nor on $S_{2}$ ), while the profits of firm 2 (the "neutral" firm) depend on the choice of location of firm 1. In particular, from expression [12] we can deduce that, in every case, firm 2 prefers that firms 1 settles in country $A$, where $F_{1}$ is smaller (since the profits of firm 2 depend negatively on $F_{1}$ ). In fact, a lower $F_{1}$ leads the "ethical" firm to undertake a higher level of CSR and charge a higher price for good 1. This, in turn, relaxes the competition at the marketing stage of the game, allowing the "neutral" firm to charge a higher price for good 2 too.

Finally, it is worth noting that both firms' profits depend negatively on $s_{0}$. In fact, when the minimum international CSR standard increases, there is less room for differentiation for the two firms, thus the competition at the marketing stage of the game is fiercer and both firms have to reduce the prices at equilibrium (see equation [13], considering that, at equilibrium, $s_{2}^{*}=s_{0}$ ).

Proposition 4. The location choice of the "ethical" firm depends on the costs of compliance with local norms and regulations $(S)$, on the costs of making CSR "visible" $(F)$ in the two countries, and on the distribution of consumers' tastes for CSR, but not on the of the minimum international standard for $\operatorname{CSR}\left(s_{0}\right)$. The location choice of the "neutral" firm instead depends on the level of $S$ and $F$ in the two countries and on the level of the minimum international standard for CSR $\left(s_{0}\right)$, but not on the distribution of consumers' tastes for CSR.

Proof. We define $\pi_{i j}$, with $i=1,2$ and $j=A, B$, as the profits attained by firm $i$ when it settles in country $j$. These depend on the values of $S$ and $F$ in each country. Each firm 
chooses to settle in the country where it achieves higher profits. Hence, firm 1 chooses to settle in country $A$ (country B) when:

$$
\pi_{1 A}>(<) \pi_{1 B}
$$

And firm 2 chooses to settle in country A (country B) when:

$$
\pi_{2 A}>(<) \pi_{2 B}
$$

Let's study the choice of firm 2 ( the "neutral" firm) first. As previously said the profits of firm 2 depend on the choice of location of firm 1 (since they depend on $F_{1}$, see condition [12]). However, when firms interact strategically to choose their location, the choice of firm 2 is not affected by the choice of firm 1. In particular, we can derive from conditions [12] and [15] that, for any location of firm 1, firm 2 will settle in country $A$ (country B) if:

$$
S_{A}-S_{B}<(>) \frac{s_{0}^{2}}{2}\left(F_{B}-F_{A}\right)
$$

As regards the "ethical" firm, we can derive from conditions [11] and [14] that firm 1 will settle in country $A$ (country B) if:

$$
S_{A}-S_{B}<(>) \frac{\left(2 v_{H}-v_{B}\right)^{4}}{162 F_{B} F_{A}}\left(F_{B}-F_{A}\right)
$$

Proposition 4 follows.

The following considerations can be deduced from conditions [16] and [17].

Condition [16] implies that the "neutral" firm will settle in the country with stricter regulations (i.e. country A, or "North") only if the difference in the costs of compliance with local regulations $\left(S_{A}-S_{B}\right)$ is more than compensated by the lower costs of undertaking a level of CSR equal to the minimum international standard level $\left(s_{0}\right)$. On the contrary, if the difference in the costs of compliance with local regulations is large "enough", the "neutral" firm will settle in country B ("South").

From condition [16] it is evident that, the lower the minimum international CSR standard $s_{0}$, the more likely firm 2 will settle in country "South", since even a small difference in the costs of compliance with local norms will induce the firm to settle there.

This help us understand the general reluctance of developing countries to set and adopt strict international CSR standards. These countries often benefit from large amounts of FDIs from developed economies, and one of the reasons of the attractiveness of developing countries for FDIs is that they are usually characterized by looser norms and regulations in the areas of labor and the environment then developed ones. With respect to this, condition [16] tells us that an increase in the international CSR standards would reduce the incentives of all the "neutral" firms to locate their production in the countries characterized by looser norms.

As regards the location choice of the "ethical" firm, condition [17] implies that firm 1 will settle in country B ("South") if the difference in the costs of implementing local norms $\left(S_{A}-S_{B}\right)$ is large enough to counteract the higher costs of making CSR "visible" to the consumers than in country A. This condition is significantly different from condition [16]: $s_{0}$ does not enter inequality [17], implying that the minimum international CSR standard 
does not affect the choice of location of the "ethical" firm ${ }^{18}$ and there is a term, $\frac{\left(2 v_{H}-v_{B}\right)^{4}}{162 F_{B} F_{A}}$, which depends from consumers' preferences for CSR. Since we assumed that consumers are distributed uniformly with unity density, $v_{\mathbf{B}}$ is equal to $v_{H}-1$ (see page 5) so $\left(2 v_{H}-v_{B}\right)^{4}$ can be written as $\left(v_{H}+1\right)^{4}$, which depends only on $v_{H}$.

Hence, the higher $v_{H}$, the larger must be the difference in local regulations $\left(S_{A}-S_{B}\right)$ in order to induce the "ethical" firm to settle in the country with looser local regulations (i.e. country "South").

The parameter $v_{H}$ has different interpretations. First of all, it can be interpreted as the average consumers' "preference" for CSR: the higher $v_{H}$, the more "ethical" are the consumers on average..$^{19}$ Secondly, this parameter also captures the heterogeneity in the "ethical preferences" of the consumers. This can be shown easily. The ratio $\frac{v_{H}}{v_{B}}=\frac{v_{H}}{v_{H}-1}$ measures the heterogeneity in consumers' preferences for CSR. Since $0<v_{B}<1$ and $1<v_{H}<2$ (cf. Assumption 1), the ratio $v_{H} /\left(v_{H}-1\right)$ is a monotonically decreasing function of $v_{H} \cdot{ }^{20}$ Hence, the higher $v_{H}$, the more homogenous are consumers' preferences for CSR.

A final consideration that can be made, is that conditions [16] and [17] suggest at least one possible way for developing countries to attract FDIs (i.e. to attract both the "neutral" and the "ethical" firms in our model). This would be to reduce $F_{B}$ (i.e. the costs of making CSR "visible" to consumers), in order to cut the difference between $F_{B}$ and $F_{A}$. For this purpose, developing countries should introduce the necessary reforms to facilitate the practice of CSR and increase its visibility. Examples of these interventions are the promotion of Public and Private Partnerships (PPPs), of a social network prone to CSR interventions, and of systems allowing to increase the reliability of CSOs, such as the Civil Society Information System (CSIS) recently introduced in some developed countries (e.g. USA and Germany). ${ }^{21}$

${ }^{18}$ This result can be somehow compared to the case of an innocuous minimum standard (see Garella [2007]). In the CSR literature, the case of a standard which is lower than the level of CSR already undertaken by firms, has been incidentally analyzed by Besley and Gathak (2007) and Brekke and Nyborg (2004).

${ }^{19}$ Since $v_{H}$ and $v_{B}$ are linked one to the other by a deterministic relationship, when $v_{H}$ increases, $v_{B}$ has to increase.

${ }^{20}$ In fact, $\frac{v_{H}}{v_{H}-1}=\frac{1}{\frac{v_{H}-1}{v_{H}}}=\frac{1}{1-\frac{1}{v_{H}}}$.

${ }^{21}$ Looking at conditions [16] and [17], there is of course another strategy to attract FDIs, which is to reduce further local norms and regulation in the areas of labor and the environment $\left(S_{B}\right)$. Leaving aside all possible ethical considerations on the opportunity of doing so, it should be noted that, in any case, all the firms located in whatever country have to comply with the minimum international CSR standard. Hence, this constitutes a sort of lower bound for the countries in the process of reducing $S_{B}$, thus limiting their possibilities of relaxing labor and environmental legislation as a way to attract more FDIs. 


\section{Comparative Statics}

Let's turn now to some considerations of comparative statics.

We start from an initial situation where both firms are located in country A ("North"), and then analyze the effects of possible variations of the minimum international CSR standard $\left(s_{0}\right)$ and of consumers' preferences for $\operatorname{CSR}\left(v_{H}\right)$.

The fact that both firms are located in country A implies that the exogenous variables respect the following conditions:

$$
\begin{gathered}
S_{A}-S_{B}<\frac{s_{0}^{2}}{2}\left(F_{B}-F_{A}\right) \\
S_{A}-S_{B}<\frac{\left(v_{H}+1\right)^{4}}{162 F_{B} F_{A}}\left(F_{B}-F_{A}\right)
\end{gathered}
$$

Conditions [18] and [19] ensures that, respectively, firm 2 (the "neutral" firm) and firm 1 (the "ethical" firm) settle in country A ("North"). In fact, when the exogenous variables $S_{A}, S_{B}, F_{A}, F_{B}$ and $s_{0}$ respect condition [18], firm 2 attains a higher profit by settling in country A than in country B. On the other hand, when the exogenous variables $S_{A}, S_{B}, F_{A}, F_{B}$ and $v_{H}$ respect condition [19], firm 1 attains a higher profit by settling in country A than in country B.

We analyse first the effects of an exogenous variation of $s_{0}$. A variation of $s_{0}$ does not affect the relative attractiveness of the two countries for firm 1 (see condition [19]), hence it does not influence the location choice of the "ethical" firm. Otherwise, it affects the relative attractiveness of the two countries for firm 2 in the following way (see condition [18]): an increase of $s_{0}$ makes country "North" even more attractive for the "neutral" firm, while a decrease of it increases the relative attractiveness of country B with respect to A and, if this decrease is large enough to invert the sign of inequality [18], it will induce the "neutral" firm to relocate in country "South".

Hence, the overall effect of an increase of the international minimum CSR standard $s_{0}$ on the location of firms is the status quo (i.e. both firms stay in country A). On the other hand, a significant reduction of $s_{0}$ could lead the "neutral" firm to relocate in country "South". In fact, as a result of the reduction of the minimum international CSR requirement, firm 2 undertakes less CSR at equilibrium, and thus the costs attached to CSR become less relevant relatively to the costs of compliance with local labor and environmental regulations, in determining the location choice.

Then, we analyse the effects of an exogenous variation of $v_{H}$. We need to recall that an increase (decrease) of $v_{H}$ indicates an increase (decrease) of the average consumers' "preference" for CSR, and also a reduction (augmentation) of the heterogeneity of these preferences (see page 14). In more practical terms, an increase of $v_{H}$ depicts the evolution from an initial situation in which only a few consumers care about the "ethical" behavior of firms and these consumers are concentrated in a few areas of the world, while the majority does not care or is simply unaware of the issue, towards one in which more people are aware of CSR and care about it when choosing where to shop. A reduction of $v_{H}$ instead 
could result from the increased buying power of consumers from developing countries, which are usually less concerned about ethical issues when choosing where to shop. This reduces the average "preference" for CSR globally and increases the heterogeneity of consumers' preferences.

In our model, a variation of $v_{H}$ does not affect the relative attractiveness of the two countries for firm 2 (see condition [18]), hence it does not influence the location choice of the "neutral" firm. Otherwise, a variation of $v_{H}$ affects the relative attractiveness of the two countries for firm 1 in the following way (see condition [19]): an increase of $v_{H}$ makes country "North" even more attractive for the "ethical" firm, while a reduction of it increases the relative attractiveness of country B with respect to A and, if this decrease is large enough to invert the sign of inequality [19], it will induce the "ethical" firm to relocate in country "South".

Hence, the overall effect of an increase of $v_{H}$ (i.e. the average consumers' preference for CSR increases and the distribution of these preferences is less heterogeneous) is the status quo (i.e. both firms stay in country "North"). On the other hand, a significant decrease of $v_{H}$ could lead the "ethical" firm to relocate in the country with the loosest labor and environmental norms (i.e. country "South). In fact, as a result of the lower consumers' preference for CSR and the increased heterogeneity of their preferences, firm 1 reduces its level of CSR at equilibrium, and thus costs of compliance with local regulations become more relevant relatively to the costs attached to CSR, in determining the location choice. Interestingly, the "neutral" firm stays in country "North", despite the stricter regulations in that country with respect to "South".

We could repeat this exercise starting with different initial situations.

For example one interesting case is when the "ethical" firm is initially located in country "North" while the "neutral" firm is in country "South".22 In our model, this implies that the exogenous variables respect the following conditions:

$$
\begin{gathered}
S_{A}-S_{B}>\frac{s_{0}^{2}}{2}\left(F_{B}-F_{A}\right) \\
S_{A}-S_{B}<\frac{\left(v_{H}+1\right)^{4}}{162 F_{B} F_{A}}\left(F_{B}-F_{A}\right)
\end{gathered}
$$

Conditions [20] and [21] determine that, respectively, firm 2 (the "neutral" firm) settles in country B ("South") and firm 1 (the "ethical" firm) settles in country A ("North").

\footnotetext{
${ }^{22}$ This is a situation which we often observe in reality, and could be determined by some elements which we did not take into consideration in our model: the possible heterogeneity of consumers' preferences for CSR across countries and the existence of transport costs (see page 11 for a discussion of this issue). In fact, if the average consumers' preferences for CSR are different across countries and there are transport costs, the two firms might find it more profitable to serve prevalently the local market, undertaking a level of CSR which reflects the average preferences of their local customers. For example, companies in developing countries, where consumers are usually less concerned about CSR, could decide to undertake a lower level of CSR than their counterparts located in developed countries, where the sophistication of consumer's demand is higher. This is what typically happens to the small and medium enterprises in developing countries, which, unless they are part of the supplychain of large multinational companies, produce goods that are sold locally and thus are not affected by the preferences of global consumers and consumers in other areas of the world.
} 
Starting from this initial situation, the overall effect of a reduction of the international minimum CSR standard $s_{0}$ on the location of firms is the status quo (i.e. the "ethical "firm stays in country "North" and the "neutral" in "South"). Otherwise, an increase of $s_{0}$, if it is large enough to invert to invert the sign of inequality [20], leads the "neutral" firm to relocate in country "North". In fact, as a result of the tightening of the international CSR standard, the costs of undertaking this new level of CSR required increase more in the country where CSR is more expensive (i.e. country "South") than in the other one (i.e. country "North"), hence the relative attractiveness of country "North" for the "neutral" firm increases.

Finally, the effects of a variation of $v_{H}$ are similar to the ones analyzed in the previous situation. In fact we have seen that a variation of $v_{H}$ affects only the relative attractiveness of the two countries for the "ethical" firm, which is located in the same country as in the previous case (i.e. country "North").

\section{Conclusions}

We developed a model of CSR as a differentiation strategy for the firms, adapting Motta (1993)'s model of vertical differentiation to the issue of CSR.

In the market there are two firms and a group of global consumers, exhibiting a preference for CSR which is uniformly distributed with unit density. We introduced quadratic costs of CSR, which can be interpreted as the costs of undertaking CSR and making it "visible" to the consumers. Other costs for the firms are the costs of compliance with country-specific labor and environmental regulations. All these costs are fixed with respect to the level of the outputs. Finally, there is an exogenous minimum international CSR standard, which is applied worldwide regardless of the country of location of the firms.

In this context, we showed that, when the market is covered and firms compete $a$ la Bertrand, the two firms choose different levels of CSR at equilibrium. One firm (the "ethical" one) undertakes a positive level of CSR, which depends negatively on the costs of CSR, targeting the more ethical consumers; the other (the "neutral" firm) undertakes a level of CSR equal to the minimum international requirement. The "ethical" firm sells at a higher price than the "neutral" one, and produces a larger output.

Then, we introduced the possibility for the firms of choosing between two countries of location. One country ("North") has stricter labor and environmental regulations than the other ("South"), which translate in higher fixed costs of production for the firms. However in country "North" the costs of undertaking CSR and making it "visible" to consumers are lower than in country "South". We showed that the profits of the "neutral" firm are always higher when the "ethical" firm settles in country "North". Nonetheless, the choice of location of the "neutral" firm does not depend on the location of the "ethical" firm.

Finally, starting from different initial locations of the two firms, we analyzed the effects of a change of the minimum international CSR standard and of consumers' preferences for CSR. We showed that a change of the international CSR standard could affect the location choice of the "neutral" firm, while a variation of consumers' preferences for CSR (i.e. a variation of the average "preference" for CSR of the global consumers and of 
the heterogeneity of these preferences) might have an impact on the location choice of the "ethical" firm. In particular, a significant increase (decrease) of the international CSR standard can determine the relocation of the "neutral" firm from country "South" to country "North" (from country "North" to country "South"), and an increase (decrease) of the average preference for CSR can determine the relocation of the "ethical" firm from country "South" to country "North" (from country "North" to country "South").

In conclusion we would like to point out some of the limits of our approach. In our paper we did not address the issue of the CSR "neutrality" on profits (cf. McWilliams and Siegel [2002]), since we could not solve the equation of the firms' profits for a unique range of the parameters. In addition, as previously mentioned, in our model we assumed that there is a generic arena of global consumers, without taking into consideration transport costs and possible cross-country heterogeneities in the distribution of consumer's tastes for CSR. It would be interesting to analyze the effect of introducing different hypotheses, such as for example different average preferences for CSR in the two countries and positive transport costs, inducing firms to sell most of their production locally. We consider this paper as the starting point for future research in this direction, with the additional objective of studying the trade patterns between the two countries.

\section{Appendix. Parameters' values allowed in the model.}

The following conditions can be derived, respectively, from Assumptions 2 and 3 (see page 7), when we substitute the equilibrium values of $s_{1}^{*}$ and $s_{2}^{*}$ determined at the second stage of the game (see Proposition 2):

$$
\begin{gathered}
s_{0}>\frac{\left(2 v_{H}-v_{B}\right)^{2}\left(v_{H}-2 v_{B}\right)}{9 F_{1}\left(v_{H}+v_{B}\right)} \\
s_{0} \leq \frac{\left(2 v_{H}-v_{B}\right)^{2}}{9 F_{1}}
\end{gathered}
$$

From conditions [22] and [23], one can deduce that the minimum CSR standard $\left(s_{0}\right)$ must be within the following range of values, expressed in terms of the other exogenous variables in the model:

$$
\frac{\left(2 v_{H}-v_{B}\right)^{2}\left(v_{H}-2 v_{B}\right)}{9 F_{1}\left(v_{H}+v_{B}\right)}<s_{0} \leq \frac{\left(2 v_{H}-v_{B}\right)^{2}}{9 F_{1}}
$$

It should be noted, however, that $F_{1}$ is not exogenous per se, but at equilibrium it depends on the location choice of firm 1. In particular, it is higher (lower) when firm 1 settles in country B (A), since we have assumed that $F_{A}<F_{B}$ (cf. page 11). In the paper we have seen that, depending on the values of the exogenous variables, at equilibrium firm 1 could settle either in country A or in country B. Hence, condition [24] must hold in both cases (i.e. for $F_{1}=F_{A}$ and $F_{1}=F_{B}$ ).

Finally, one should note that a necessary condition for this inequality to hold is the following: $v_{H}-2 v_{B} \leq v_{H}+v_{B}$. Since $v_{H}=v_{B}+1$, that is equivalent to: $v_{H} \geq 1$. 


\section{Bibliography}

Amacher, Gregory S., Koskela, Erkki and Markku Ollikainen (2004), Environmental Quality Competition and Eco-Labeling, Journal of Environmental Economics and Management, Vol. 47, pp. 284-306.

Balboni, Fabio, Charles-Soveral, Wayne and Brigitte Levy (2008), New Perspectives on Corporate Social Responsibility, Caribbean Development Review, Issue N. 1, UNECLAC, pp. 17-36.

Bagnoli, Mark and Susan G. Watts (2003), Selling to Socially Responsible Consumers: Competition and the Private Provision of Public Goods, Journal of Economics and Management Strategy, Vol. 12, pp. 419-445.

Baron, David P. (2001), Private Politics, Corporate Social Responsibility, and Integrated Strategy, Journal of Economics and Management Strategy, Vol. 1, pp. 7-45.

Baron, David P. (2007), Corporate Social Responsibility and Social Entrepreneurship, Journal of Economics \& Management Strategy, Vol. 16, pp. 683-717.

Baumol, William J. (1991), (Almost) Perfect Competition (Contestability) and Business Ethics, in Baumol W.J. and Blackman, S.A.B. (1991) (Eds) Perfect Markets and Easy Virtue: Business Ethics and the Invisible Hand, Cambridge, MA, Blackwell Publishers.

Becchetti, Leonardo and Furio Camillo Rosati (2005), Globalization and the death of distance in social preferences ad inequity aversion: empirical evidence from a pilot study on fair trade consumers, Working Paper N. 209, CEIS, University of Tor Vergata, Rome.

Becchetti, Leonardo, Giallonardo, Luisa and Maria Elisabetta Tessitore (2005) Corporate Social Responsibility and Profit Maximizing Behaviour, Working Paper N. 219, CEIS, University of Tor Vergata, Rome.

Becchetti, Leonardo, Federico, Giorgio and Nazaria Solferino (2005), The Game of Social Responsibiltiy: A Product Differentiation Approach, Working Paper N. 15, Cleonp, University of Forlì.

Besley, Timothy and Maitreesh Ghatak (2007), Retailing Public Goods: The Economics of Corporate Social Responsibility, Journal of Public Economics, Vol. 91, pp. 1645-1663.

Boom, Annette (1995), Asymmetric International Minimum Quality Standards and Vertical Differentiation, The Journal of Industrial Economics, Vol. 43, pp. 101-119.

Bonanno, Giacomo (1986), Vertical differentiation with Cournot Competition, Economic Notes, Vol. 15, pp. 68-91.

Brekke, Kjell A. and Karine Nyborg (2004), Moral Hazard and moral motivation: Corporate Social Responsibility as labour market screening, Memorandum $n^{\circ} 25 / 2004$, Department of Economics,University of Oslo.

Collier, Jane and Rafael Esteban (2007), "Corporate Social Responsibility and Employee Commitment", Business Ethics: A European Review, Vol. 16, N. 1, pp. 19-33. 
D’Aspremont, Claude, Gabszewicz, Jean Jaskold and Jacques-François Thisse (1979), On Hotelling's Stability in Competition, Econometrica, Econometric Society, Vol. 47, pp. 114550 .

Garella, Paolo G. (2003), The effects of Minimum Quality Standards: Better or Worse Products, Working Paper N. 484, Department of Economics, University of Bologna.

Garella, Paolo G. (2004), Are Innocuous Minimum Quality Standards really innocuous, Working Paper N. 515, Department of Economics, University of Bologna.

Husted, Bryan W. And José de Jesus Salazar (2006), Taking Friedman Seriously: Maximizing Profits and Social Performance, Journal of Management Studies, Vol. 43, pp. 75-91.

Kelsey, David and Frank Milne (2006), Externalities, monopoly and the objective function of the firm, Economic Theory, Vol. 29, pp. 565-589.

Lambertini, Luca and Gianpaolo Rossini (2003), Vertical Integration and Differentiation in an Oligopoly with Process Innovative R\&D, Working Paper N. 468, Department of Economics, University of Bologna.

Maxwell, John W, Lyon, Thomas P. and Steven C. Hackett (2000), Self-Regulation and Social Welfare: The Political Economy of Corporate Environmentalism, Journal of Law and Economics, Vol. XLIII, pp. 583-617.

Manasakis, Consantine, Mitrokostas, Evangelios and Emmanuel Petrakis (2007), Corporate Social Responsibility in Oligopoly, Working Paper N. 707, University of Crete, Department of Economics, revised.

Mitrokostas, Evangelios and Emmanuel Petrakis (2007), Public Policy and Private CSR Activities: Complements or Substitutes?, CSR Working Paper Series, Fondazione Eni Enrico Mattei.

McWilliams, Abagail and Donald Siegel (2002), Corporate Social Responsibility: A theory of the firm perspective, Academy of Management Review, Vol. 28, pp. 117-127.

McWilliams, Abagail, Siegel, Donald and Patrick M. Wright (2006), Corporate Social Responsibility: Strategic Implications, Journal of Management Studies, Vol. 43 , pp. 1-18.

Motta, Massimo (1993), Endogenous Quality Choice: Price vs. Quantity Competition, The journal of Industrial Economics, Vol. 41, pp. 113-131.

Shaked, Avner and John Sutton (1982), Relaxing Price Competition Through Product Differentiation, Review of Economic Studies, Vol. 49, pp. 643-661.

Tirole, Jean (1998), The theory of industrial organization, MIT Press, Cambridge, MA.

Varian, Hal R. (1992), Microeconomic Analysis, 3rd edition. W. Norton and Company Inc., New York, NY. 